\title{
Control and Automation of an Industrial Food Dryer
}

\author{
Héctor García Estrada ${ }^{1}$, Angelo Pastrana Manzanero' ${ }^{1}$, Lilia Leticia Méndez Lagunas ${ }^{3}$, \\ Juan Rodríguez Ramírez ${ }^{\mathbf{3}}$, María Guadalupe Ramírez Sotelo², \\ Agustín Ignacio Cabrera Llanos ${ }^{1}$ \\ ${ }^{1}$ Instituto Politécnico Nacional, Unidad Profesional Interdisciplinaria de Biotecnología, \\ Departamento de Bioprocesos, Mexico City, Mexico \\ ${ }_{2}^{2}$ Instituto Politécnico Nacional, Unidad Profesional Interdisciplinaria de Biotecnología, \\ Departamento de Bioingeniería, Mexico City, Mexico \\ ${ }^{3}$ Instituto Politécnico Nacional, Centro Interdisciplinario de Investigación para el Desarrollo \\ Integral Regional, Laboratorio de Tecnología Agroalimentaria, Oaxaca, Mexico \\ aicllbuda@yahoo.com
}

\begin{abstract}
In this paper, the development of a system of automation and control designed for the optimization of the operation of an industrial dryer is presented. The system was divided in three stages, such as: acquisition of variables, design of interfaces and the programming of the system. A series of transducers for the variables were used in the first stage. The development of the electronic circuits was used as an interface with the acquisition and processing of data card NI myRIO-1900. The stage of the development of the programming was made through the software known as LabVIEW, using a PID controller for the development of each control giving: temperature, relative humidity and air velocity. Controlling and visualizing these 3 parameters required a correct evolution on the dynamics of the drying process. The evolution of the variables described with the adjusted parameters is shown for PID controllers.
\end{abstract}

Keywords: industrial dryer, control PID, myRIO-1900, LabVIEW.

\section{Introduction}

The food industry has developed many techniques the drying food for diverse purposes. One technique is convective drying, where the heat is transferred to the solid by a hot air stream, which is driven by fans [1]. The dryer that was automated is located at the facilities of the Agro-alimentary Technology Laboratory of the Interdisciplinary Research Center for Regional Integral Development Oaxaca Unit (CIIDIR), of the National Polytechnic Institute.

This dryer has modules of temperature, humidity and air velocity. Each of these modules has its own acquisition and regulation system. 
Héctor García-Estrada, Angelo Pastrana-Manzanero, Lilia-Leticia Méndez-Lagunas, et al.

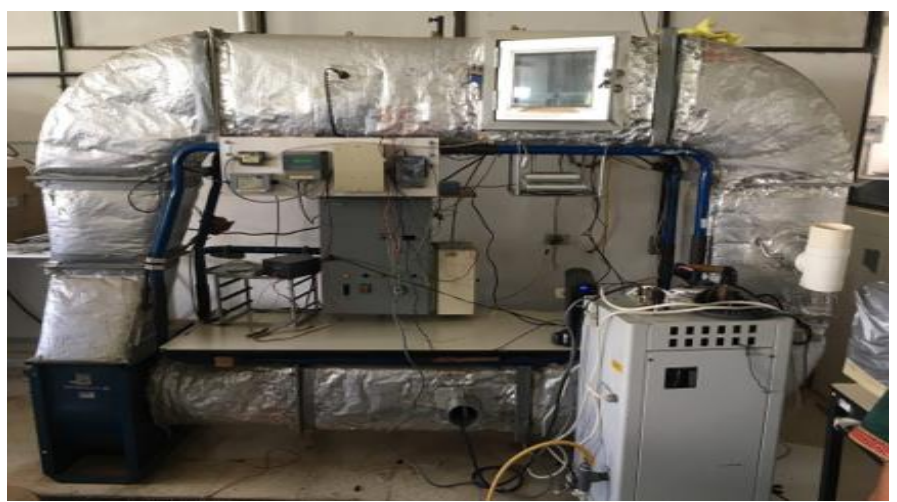

Fig. 1. Continuous flow dryer.

\subsection{Transducers}

The transducers consist of a group of instruments with dedicated microprocessors. The HMP230 transmitter series of Vaisala perform measurements of relative humidity and temperature. Output signals can be configured at measurement ranges within certain limits. It also has 2 types of analog outputs, current output from 0 to $20 \mathrm{~mA}$ and voltage output from 0 to $10 \mathrm{~V}$ maximum [2].

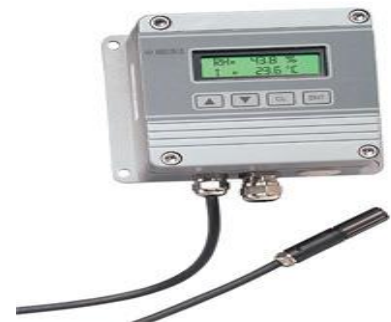

Fig. 2. Model HMP230 transducer of the Vaisala brand.

The AVT55, AVT65 and AVT75 air speed transducers are ideal at temporary and permanent installations for measuring air velocity. One of the advantages of using these models is that they contain calibration curves that provide output signals with linear response, which allows them to be adaptable to data acquisition systems [3].

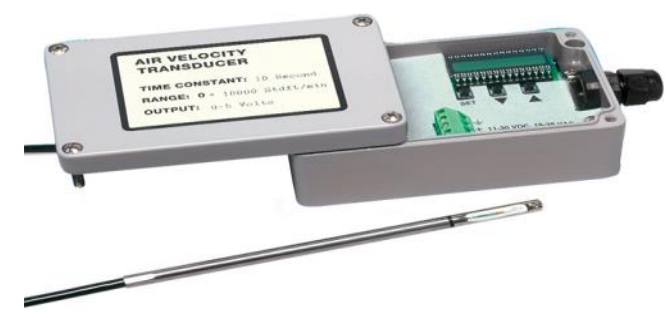

Fig. 3. Alnor AVT55 air speed transducer. 


\subsection{Proportional Integrative Derivative Controller (PID)}

A PID is a second order controller, with an integrator. PID controllers allow control actions from a measured value and a desired value, allowing a quick and easy application in industrial processes, since they only need a sensor that acquires the process variable and an actuator that reacts to the control output. The equation of a controller with this combined action is found in the following Equation (1):

$$
u(t)=K_{p} e(t)+K_{I} \int_{0}^{t} e(\tau) d \tau+K_{D} \frac{d e(t)}{d t} .
$$

Where $u(t)$ represent the output control, $K p, K i$ and $K d$ the gains in each stage and $e(t)$ is the inherent error in the system. Empirical researches show that the structure of the PID usually has enough flexibility to achieve excellent results in many control applications [4].

\section{Methodology}

The automation of the dryer is divided in three stages, which are:

- Acquisition and measurement of the variables to be controlled.

- Design of the interface circuits required by the system.

- Programming of the controls in LabVIEW.

Below is a general outline of the designed system followed by the development of each of the three mentioned stages and the results.

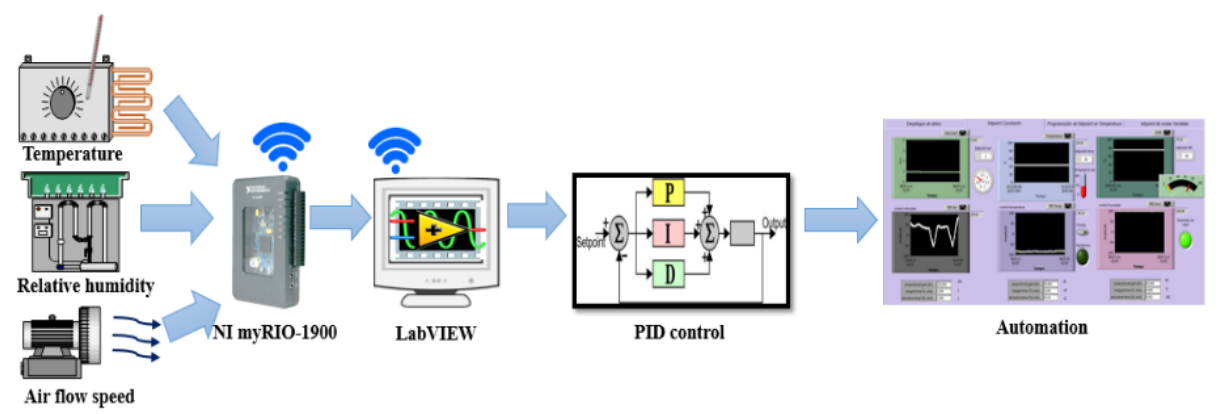

Fig. 4. General scheme of the designed system.

\subsection{Variables Acquisition}

For the acquisition of the variables, both transducers were set-up in order to acquire the output signals in voltage, avoiding the use of adequacy circuits.

For the air velocity transducer, the output signal and the measurement range were in a range of 0 to 5 volts and 0 to 5 meters per second, which achieved a 1:1 ratio in terms of voltage output and air velocity. 
For the transmitter of relative humidity and temperature, the output signals were of 0 to 5 volts. The measurements intervals in both variables were from 0 to 100 , in percentage for relative humidity and degrees Celsius for temperature, thus making a slope adjustment to obtain the variables.

\subsection{Interface Circuits}

For each process there was a device that was responsible for compensating the variables. In the case of the air speed of the dryer, there is a two-phase alternating current motor as a fan; the regulation of the rotation speed of this engine was implemented by the frequency converter SAMI 018MD2. As the air speed depends directly on the speed of the motor rotation, the output of the speed control is the frequency of operation of the converter.

The input of the frequency converter in voltage was of $0-10 \mathrm{~V}$. This input was achieved using one of the myRIO's analog outputs. Since the analog outputs of the mmyRIO are in the range of $0-5 \mathrm{~V}$, a circuit was necessary to amplify the signal and equalize it with the interval of the input of the frequency converter. For this, an OPAM array was used composed of two inverting amplifiers. The first gives the necessary gain while the second corrects the polarity. Because the frequency converter is a power system, a diode was added to the output of the OPAMS to protect both the circuit and the card against any return current.

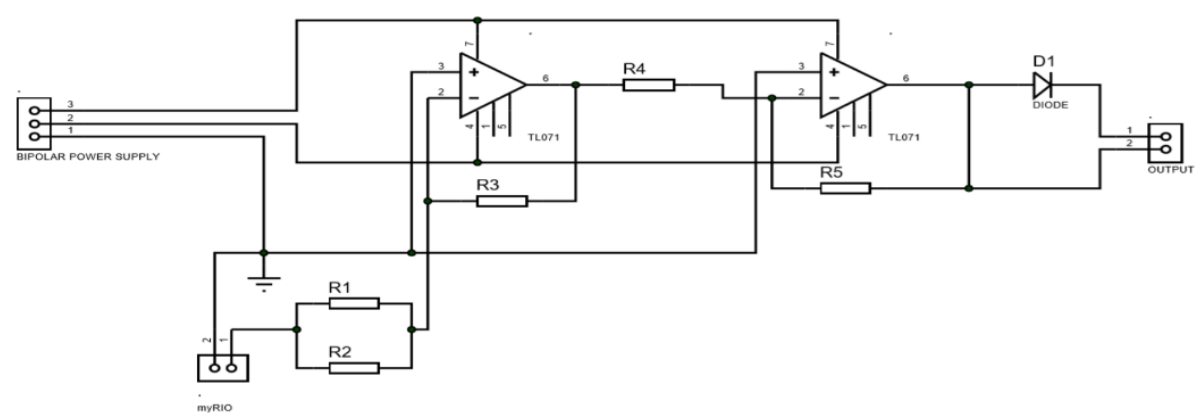

Fig. 5. Adequacy circuit of the myRIO analog output.

On the other hand, the output of the temperature control is a finned resistor for air heating fed to $220 \mathrm{~V}$. To protect the system and prevent damage on the resistor, there is a safety stage that does not allow the activation of the resistor unless the fan is on. For this, the resistor is actioned by a solid-state relay (SSR3-440B), which can operate with an input and an output operation of $120 \mathrm{~V}$ and $450 \mathrm{~V}$ in alternating current [5].

To control the resistor, it was necessary to design an interface circuit between the myRIO and the relay. For this, the optocoupler model MOC4011 was used for its output in the form of phototriac [6]. To complete the activation circuit the triac BTA12 was used with an array of resistors, managing to control the operation of the resistance by means of a digital output of the myRIO [7]. 


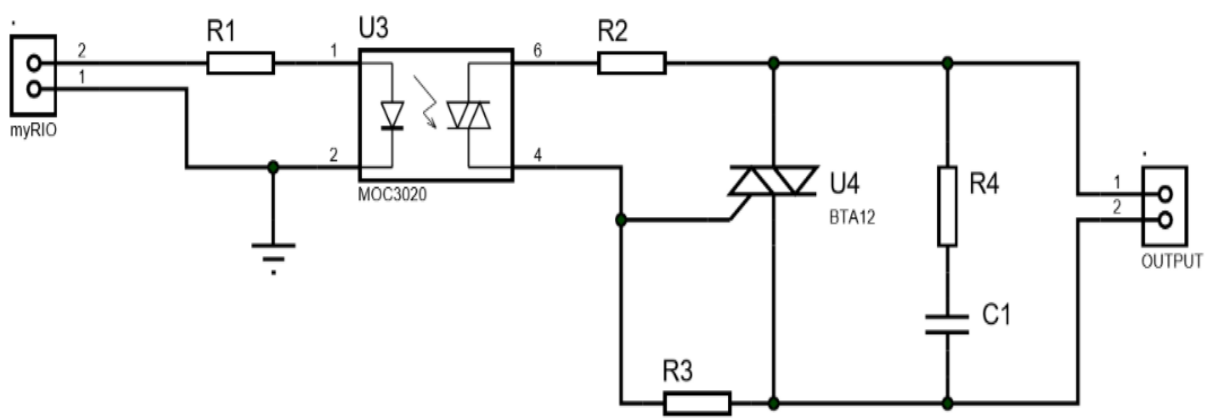

Fig. 6. Power circuit for the activation of the resistance and steam generator.

In the case of humidity variable, a steam generator was used. Within a control output, steam was injected to the dryer by this generator. This device operates with an alternating current of $220 \mathrm{~V}$, controlling in this way the steam flow by electro valves. Because the circuit design applied to the resistor control operates within the same parameters as the steam generator, it is implemented again with the humidity generator.

\subsection{Programming and Tuning of the Controls}

The programming and tuning of the controls were made using LabVIEW with the "Control and Simulation" module. The type of controller employed is the PID controller. This is due to the ease of implementation. To perform the necessary tests on the controls, a virtual instrument was developed in LabVIEW where the parameters could be varied while the program was running.

The PID tuning was made with a heuristic approach, comparing the behavior when making changes in the gains. Each of the three controls was tuned separately obtaining different values for the constants of each. The control outputs of the system were programmed in different ways. In the case of the output of the speed control this was set-up to use an analog output of the myRIO together with the adequacy circuit.

For the temperature and humidity outputs, the outputs were set-up in such a way that the output of the control was positive, either the resistance or the electro valve of the steam generator were activated. Otherwise, the systems were turned off. This was achieved by the digital outputs of the myRIO.

\section{Results}

A continuous flow dryer was automated through the implementation of PID controls in the variables with a virtual instrument for set-point definition, the variables and control responses. The control outputs behaved in such way that the drying process was not affected. Tuning the controls by test and error, the gains were reached to values with a good performance as presented below: 
Héctor García-Estrada, Angelo Pastrana-Manzanero, Lilia-Leticia Méndez-Lagunas, et al.

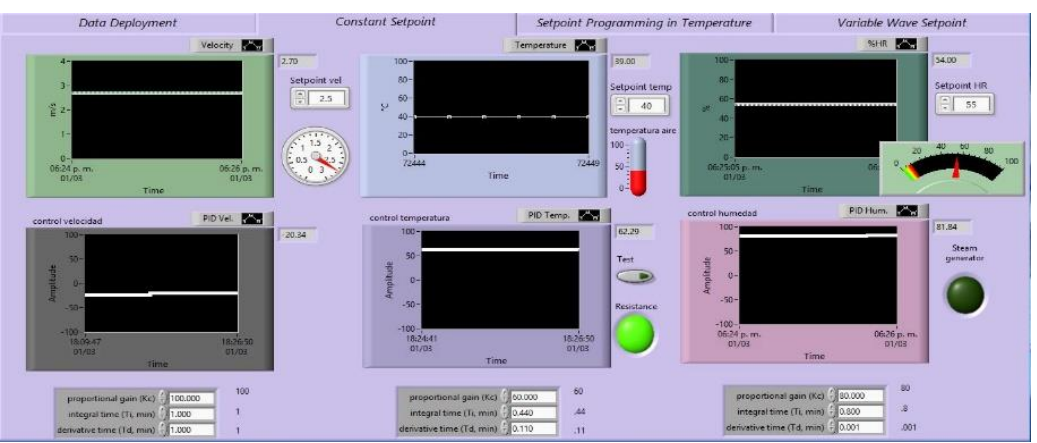

Fig. 7. Front panel virtual instrument for the programming of the controls.

In the case of speed control with gain values of $K p=100, K i=1$ and $K d=1$, the following behavior was achieved. In the graph a set point of $2.5 \mathrm{~m} / \mathrm{s}$ was used with an error in the steady state of $\pm 0.1 \mathrm{~m} / \mathrm{s}$.

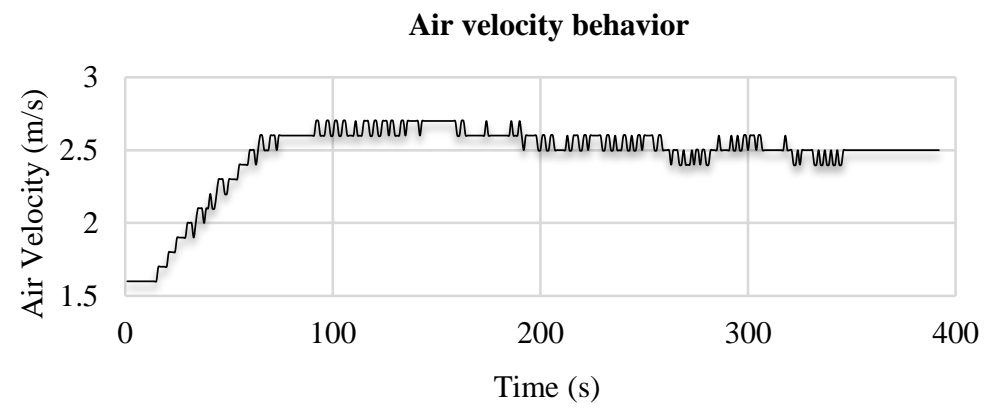

Fig. 8. Speed control behavior graph.

To control humidity with gain values of $K p=80, K i=0.8, K d=0.001$ also a set point of $50 \%$ with an error in the steady state of \pm 6.85 percent relative humidity; this value being acceptable for the experiments that require it.

Humidity behavior

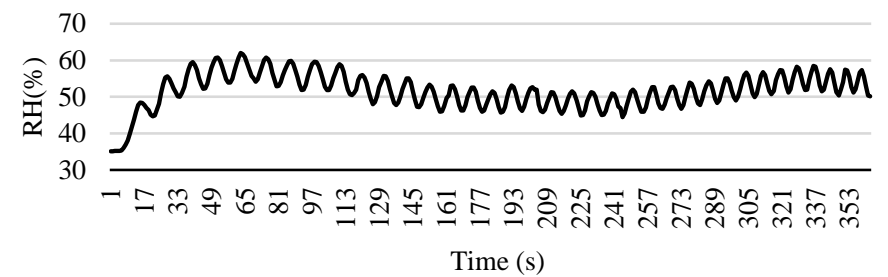

Fig. 9. Relative humidity control behavior graph. 
Finally, the temperature variable with gain values of $K p=60, K i=0.44, K d=0.11$ and a set-point of $40{ }^{\circ} \mathrm{C}$ can be controlled with an error in the steady state of \pm 1.65 degrees centigrade, an acceptable range for the system. The values of gain in each control can be modified according to the experimental conditions required by the researchers of the unit [6].

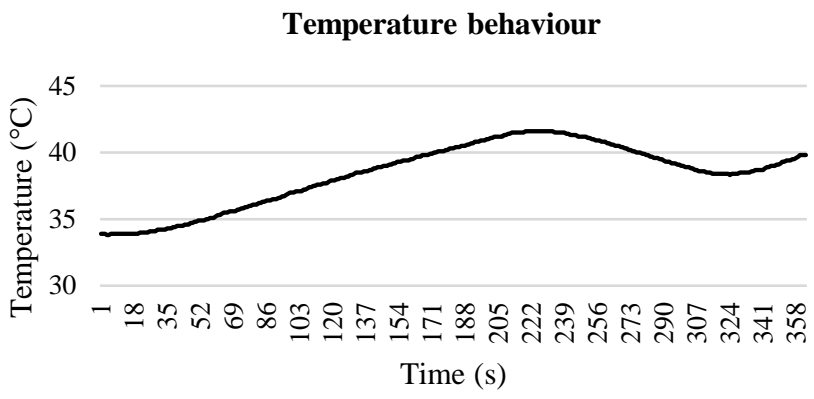

Fig. 10. Temperature control behavior graph.

We know that one of the main reasons to automate a system is the increase of productivity levels, reduction of the energy consumption, increase of the reliability of the result and, of course, the optimization of the human resource inside the facilities of the laboratory allowing the user to develop other activities while the process is taking place.

The maintenance programs for the NI myRIO and the interface circuits are minimal, since, only spare parts of the electronic components would be needed within the interface circuit. Finally, it is important to highlight that at most cases it is always cheaper to use new instruments than repair an older one because the dryer presented in this work used a FieldPOINT acquisition system of the FP-1000 series changing the maintenance cost of this system, and added to that, modules that are difficult to obtain in the market $[7,8]$.

Due to the characteristics of the PID controller and the form of tuning that was used, a fast and functional control system is obtained according to the characteristics for which the dryer is required. In addition, the ease of use of control through the LabVIEW module makes the PID control system a useful tool for this process, without ruling out the possibility of implementing in future work other more modern control systems [9]. Sometimes it is very difficult to obtain the model of the plant which is due to different factors. As future work the corresponding model of the system could be made, taking the time necessary for its construction.

\section{Conclusions}

The variables of temperature, relative humidity and air speed in a dryer tunnel were controlled by using PID-type controllers, achieving an evolution within acceptable parameters in the food drying process, allowing the drying process to comply with the conditions imposed by the researchers of CIIDIR Oaxaca. The realization of this project 
implies an innovation in the system, allowing a control of the process, in a more effective way, due to the friendly handling of the parameters of the PID controllers, shown in the front window of the program carried out. The updating of the data acquisition system by the myRIO allowed the development of all the control algorithms, to be used in a single computer. Finally, by leaving the changes enabled gain values of each of the controls to perform different tests at the user's pleasure, thus observing different behaviors in the dynamics of the system.

\section{References}

1. Fito-Maupoey, P., Andrés-Grau, A. M., Barat-Baviera, J. M., Albors-Sorolla, A. M.: Introducción al secado de alimentos por aire caliente. Universitat Politécnica de Valencia, Dorman (2016)

2. Vaisala: HMP230 Series Transmitters user's guide. Finland: Vaisala (2002)

3. Alnor: Air Velocity Transducers Models AVT55, AVT65, and AVT75. Estados Unidos: Alnor (2010)

4. Mazzone, V.: Controladores PID. Argentina: Universidad Nacional de Quilmes (2002)

5. Asiaon Relay: SSR3 Solid State Relay. China: Asian Relay (2010)

6. García, H., Pastrana, A., Méndez, L., Rodríguez, J., Ramírez, M., Cabrera, A.: Automatización de un secador de flujo continuo por medio de la tarjeta myRIO-1900 y LabVIEW. En: Congreso Internacional sobre Innovación y Desarrollo Tecnológico (2018)

7. Velásquez, J.: Cómo justificar proyectos de automatización. Industrial data, 7(1), pp. 7-11 (2004)

8. Gómez-Gómez, N.: Cinéticas de ácido pirúvico durante el proceso de secado constante y variable del ajo. Tesis en Ciencias en Conservación y Aprovechamiento de los Recursos Naturales, Oaxaca, Oax., Instituto Politécnico Nacional (CIIDIR) (2008)

9. Ruiz-Alcántara, A. H.: Control Difuso Vs Control PID: Análisis y Simulación Numérica. Tesis en Ciencia Básicas en Ingeniería, Pachuca de Soto: Universidad Autónoma del Estado de Hidalgo (2007) 